\title{
Visceral Adiposity Syndrome and Cardiometabolism
}

\author{
Heno F Lopes, ${ }^{1}$ Brent M Egan²
}

\begin{abstract}
The distribution of fat in the human body is related to hemodynamic and metabolic homeostasis. Brown fat is inversely related to body mass index and is associated with a lower probability of developing diabetes. Beige adipose tissue shares some functional characteristics with brown adipose tissue. White adipose tissue constitutes the majority of the fatty tissue and is mainly distributed in the subcutaneous and abdominal cavity. Intra-abdominal white fat has gained prominence in recent years for its association with cardiovascular risk factors and higher cardiovascular mortality. This review article discusses the human adaptation in the environment, a sympathovagal and hypothalamic-pituitary-adrenal imbalance as a possible cause of increased visceral adiposity and its consequences on cardiometabolism.
\end{abstract}

Key words: Visceral adiposity; Sympathetic nervous system; Hypothalamic-pituitary-adrenal axis; Cardiometabolism.
(1) Heart Institute (InCor) Medical School, Universidade de Sao Paulo, Sao Paulo, Brazil.

(2) University of South Carolina School of Medicine - Greenville, Greenville, SC, USA.

Correspondence:

HENO F LOPES

E: hipheno@gmail.com

\section{ARTICLE INFO}

Received: 10 June 2021 Accepted: 16 June 2021

\section{Introduction}

The adaptation of human beings to the environment over thousands of years was gradual. Possibly the fight for survival contributed to the development of adaptive responses that were incorporated into the genes of the human organism and underwent changes over time. A response to environmental stress, well known today, was described by Cannon and De La Paz in $1911^{1}$ as a fight-or-flight reflex. The stress coming from the environment activates the cerebral cortex and is directed to centres (areas) in the midbrain that regulate our homeostasis. According to Cannon's description, ${ }^{1}$ the fight-or-flight reaction is characterised by neuroadrenergic activation and catecholamine release. The catecholamines released in the nerve endings and blood circulation will have an effect on different parts of the body, preparing for fight or flight. Among the changes that occur in the body due to the reflex, the following stand out: increased blood pressure, vasodilation of blood vessels in the skeletal musculature, heart and brain, vasoconstriction in the blood vessels to the intestine and kidneys, muscle relaxation smooth bowel and bladder, bronchodilation, increased heart rate and heart contraction force, mydriasis, increased gluconeogenesis, increased liver glycolysis, decreased fluid secretion in most glands.

Is there a relationship of the fight-or-flight (chronic) reaction with the clustering of cardiovascular risk factors (metabolic syndrome), with a high prevalence in the adult population in a large number of countries in the world? ${ }^{2}$ This clustering of cardiovascular risk factors has been much discussed in the last 30 years. However, the main pathophysiological mechanism for this condition remains unclear. Insulin resistance has been identified as the main pathophysiological mechanism for the association of visceral obesity with other risk factors (dyslipidaemia, hyperglycaemia, hypertension). According to observations 
presented in this paper, there is strong evidence that sympathovagal imbalance and activation of the hypothalamic-pituitary-adrenal (HPA) axis may be responsible for the visceral adiposity syndrome (VAS). ${ }^{3}$ In this review the different types of fat in the body, visceral adiposity and the implication of visceral adiposity in cardiometabolism will be addressed.

\section{Adipose tissue}

Fat tissue is the body's largest energy reserve. The main component of adipose tissue (triglycerides) is formed from the two largest caloric sources in nature: carbohydrates and fat. Today, it is known that adipose tissue performs different functions in the body. Fat cells are classified into brown, beige and white fat. These cells are distributed in different places in the body so that each group of fat cells performs its function independently, but integrated.

Brown adipose tissue (BAT) has the function of providing heat (thermogenesis) to the body and becomes more evident in positron emission tomography/computerised tomography (PET/CT) images when the individual is exposed to cold. Leitnera et al, using the PET/CT technique, described the anatomical distribution and functional capacity of BAT in non-obese and obese individuals after exposure to cold. ${ }^{4}$ BAT is predominant in women and has an inverse relationship with the body mass index. ${ }^{5}$ In morbid obese patients BAT is functionally less active and it is expressed again after weight loss in this population. ${ }^{6}$ Due to its inverse relationship with the body mass index, ability to expend energy in form of heat, and its association with a lower risk of type 2 diabetes, BAT has been seen as a therapeutic target. ${ }^{7}$

The existence of adipose tissue other than brown and white, biochemically capable of producing heat, was found by Petrović et al in $2010 .{ }^{8}$ Beige adipose tissue, adipocytes infiltrating white adipose tissue (WAT), share some functional characteristics with brown adipocytes. However, the thermogenic capacity of beige adipocytes is only $10 \%$ of brown adipocytes. ${ }^{9}$ Better knowledge of the origin of beige adipose tissue from physiological and pharmacological stimuli can result in a greater probability of using these adipocytes as a therapeutic target. According to Shao et al ${ }^{10,11}$ the use of transcription factors to recruit WAT such as thermogenic fat (brown/beige) is a promising therapeutic opportunity for the future.

WAT constitutes most of the fat tissue in the human body and is located mainly in the subcutaneous and abdominal cavity. The increase in abdominal circumference does not necessarily represent a large amount of visceral adipose tissue (VAT), as expansion of subcutaneous abdominal fat may predominate in some individuals with weight gain. ${ }^{12}$ The visceral adipose tissue (intra-abdominal) has several characteristics that differentiate it from subcutaneous adipose tissue (SAT): larger adipocytes, venous drainage to the portal system, greater sensitivity of adrenergic receptors $\left(\beta_{3}\right.$ and $\left.\alpha_{2}\right)$ to catecholamine stimulation, higher level of beta adrenergic receptors $3 .^{13}$ In addition to the structural, functional and autonomic modulation differences, VAT is different from SAT in relation to gene expression. ${ }^{14,15}$ The main focus of this review is to discuss a possible mechanism for concentration of active visceral white adipose tissue in the abdominal cavity, the autonomic modulation and the cardiometabolic reflex resulting from this active adipose tissue.

\section{Visceral adiposity syndrome - possible pathophysiological mechanism}

The grouping of cardiovascular risk factors that includes visceral fat (central obesity), dyslipidaemia, high blood glucose and high blood pressure gained greater prominence based on the observations of Reaven in $1988 .{ }^{16}$ However, in 1761 JB Morgagni had already drawn attention for the association between visceral obesity, hypertension, hyperuricaemia, atherosclerosis and the obstructive sleep apnoea syndrome. ${ }^{17}$ Since Morgagni's observations until today, different authors have drawn attention to the association of obesity and other risk factors with cardiovascular disease. ${ }^{18,19}$ Based on the observations of Reaven, ${ }^{16}$ different definitions for this grouping of risk factors emerged and are still in force today. ${ }^{20-23}$

However, in recent years, much more has been learned about the components of the grouping of cardiovascular risk factors described by Reaven ${ }^{16}$ and their possible pathophysiological mechanisms. Uric acid as described by Morgagni et $\mathrm{al}^{17,24}$ and 
other substances seem to be part of this risk factor grouping. Adiponectin, for example, emerged as an important component and biomarker for this grouping of risk factors. ${ }^{25-27}$ For these reasons presented here and others, this grouping of risk factors is seen as a more complex syndrome, whose main pathophysiological mechanism is activation of the sympathetic nervous system (SNS).

There is a tendency in the literature to associate increased sympathetic tone with obesity and comorbidities. ${ }^{28}$ Experts in the assessment of sympathetic activity have associated overweight, obesity and metabolic alterations as possible causes of increased sympathetic activity. ${ }^{29}$ However, some evidence points to the increased activity of the SNS and of the HPA axis as a cause of visceral obesity and comorbidities. ${ }^{30,31}$ This increase in sympathetic activity and greater activation of the HPA axis would occur from environmental factors (salt, stress), especially in those who have a genetic predisposition to it. Children of hypertensive parents, for example, would be a population predisposed to develop visceral obesity and metabolic alterations. In this sense, higher values for body mass index (BMI), blood pressure, insulin, insulin-glucose ratio, norepinephrine and lower HDL-cholesterol values in normotensive young children of malignant hypertensive parents have been observed. ${ }^{32}$ In the review by Feber et $\mathrm{al}^{33}$ they draw attention to the importance of the sympathetic switch hyperactivity in the pathophysiogenesis of hypertension and its relationship with central obesity in children.

SNS, hypertension, and insulin resistance - the grouping of risk factors resulting from increased activity of visceral fat, VAS, has as likely and main initial mechanism and in its maintenance the hyperactivation of the SNS. Thorp and Schlaich ${ }^{34}$ discussed the importance of the SNS in regulating metabolism and propose sympathetic hyperactivity as a possible pathophysiological mechanism of metabolic abnormalities. They also point to the chronic increase in sympathetic activity as a potential cause of "metabolic syndrome" through increased blood pressure, insulin resistance, increased triglycerides and obesity. In addition, the skeletal muscle of the obese hypertensive patient extracts less glucose when stimulated compared to the normotensive one, possibly due to changes in microcirculation re- sulting from hypertension..$^{35}$ On the other hand, the use of prazosin, an alpha 1 adrenergic receptor blocker, resulted in an improvement in insulin resistance in obese hypertensive patients. ${ }^{36}$ In the study by Grassi et al, ${ }^{37}$ sympathetic activity, assessed by microneurography, was greater in patients with clustering of risk factors and even greater in those in which hypertension was part of the risk factors. These observations point to an association of sympathetic activity with high blood pressure, insulin resistance and metabolic changes. In a study involving individuals with clustering of risk factors for cardiovascular disease (metabolic syndrome according to ATP III) ${ }^{22}$ we showed that those with 3 risk factors or more, including hypertension, had a higher low frequency (LF) component in the spectral analysis, worse metabolic, inflammatory, prothrombotic profile, and lower level of adiponectin compared to those without the high blood pressure component. ${ }^{38}$ In this study, the BMI and fat percentage were identical in both groups. The activity of the SNS is increased at baseline and after different types of stress in children of hypertensive patients even before the development of arterial hypertension. ${ }^{39,40}$ Thus, the activity of the SNS is increased before the onset of hypertension, in the initial phase and becomes more evident as the severity of hypertension increases. ${ }^{41}$

What is the relationship of sympathetic activity with hypertension and visceral adiposity? The increase in sympathetic activity results in the activation of other systems such as the renin-angiotensin aldosterone system (RAAS). It is known that catecholamines and angiotensin II play an important role in vascular and cardiac remodelling and are also related to glucose metabolism. Vascular remodelling begins in the endothelium, compromising vasodilation, and is influenced by the SNS. ${ }^{42}$ Sympathetic activation compromises the endothelium and also results in cardiac and vessel smooth muscle hypertrophy ${ }^{40,}{ }^{41}$ In addition, central noradrenergic abnormality may be responsible for the increase in peripheral vascular tone observed in arterial hypertension..$^{45}$ The SNS activates the RAAS via the $\beta 1$ receptor. Activation of the RAAS contributes to greater muscle contraction and growth of the vessel involving complex mechanisms. ${ }^{46}$ The increase in smooth muscle tone of peripheral vessels, under the influence of the sympathetic nervous system and the RAAS, will result in greater vascular resistance, increased afterload and greater cardiac work. A consequence of this hemodynamic imbalance will 
be greater metabolic demand and consequently the hypertensive patient will have a higher metabolic rate at baseline and after physical activity. ${ }^{47,48}$ The greater sympathetic activity resulting from environmental factors (stress, salt, ...) results in what the Russians called it in the 1950s "cardiovascular neurosis" to explain the pathophysiology of high blood pressure. ${ }^{49}$ However, this "cardiovascular neurosis" does not just result in increased blood pressure. In the present interpretation, based on current literature, the imbalance of the autonomic nervous system (increase in sympathetic activity) results in greater demand metabolic, consequently higher energy expenditure. The greatest energy expenditure will be supplied by fatty acids from visceral fat. This increased demand for visceral fat results in the differentiation of adipocytes in terms of size and function. ${ }^{50}$ This intra-abdominal (visceral) fat deposition we call VAS resulted from a poor adaptation to the environment over many years.

Energy expenditure and visceral fat - the body's main sources of energy are carbohydrates and fat. Carbohydrates account for approximately 2 to $8 \%$ and fat replenishes for 92 to $98 \%$ of stored energy. ${ }^{51}$ It is known that basal metabolism accounts for $60-70 \%$ of the total energy expended. Since the energy reserve in the form of carbohydrates is low, the body with a high metabolic rate, as in the case of arterial hypertension, ${ }^{52,53}$ will use fatty acids as an energy source with greater intensity than normotensive individuals. The easiest fat to use is from VAT. In a stressful situation, the body increases sympathetic activity and this increase in sympathetic activity will result in lipolysis to provide fatty acids as an energy source. ${ }^{54}$ The chronically activated SNS in hypertensive patients ${ }^{41}$ will contribute to the increase in fatty acids and increased fatty acids in the circulation purportedly contribute to insulin resistance..$^{52,53}$ Therefore, insulin resistance in VAS may be a consequence changes in microcirculation resulting from hypertension, ${ }^{35}$ and a "competition" of glucose and fatty acid metabolism as described by Randle $^{57}$ for more than 50 years as the "fatty-acid syndrome". In summary, VAS, called metabolic syndrome, may be the result of a higher turnover of fatty acids as a result of a higher metabolic demand (increased sympathetic activity).

\section{Visceral adiposity syndrome and cardiometabolism}

Analysing something complex in a simplistic way, we can say that the growth of cardiometabolic conditions (obesity, metabolic syndrome, and diabetes) in recent years ${ }^{58}$ may be a consequence of an autonomic imbalance (predominance of the sympathetic component) that increases the metabolic demand resulting in greater mobilisation of fatty acids from visceral fat, leading to insulin resistance and all the known consequences. Sympathetic activity, assessed by microneurography, has a better association between visceral fat (intra-abdominal) than total fat and subcutaneous fat. ${ }^{59}$ Sympathetic activity, assessed using electrocardiographic parameters, is also associated with visceral fat. ${ }^{60}$ In addition to activation of the SNS to the VAT the activation of the HPA axis may be related to the pathophysiogenesis of the VAS, ${ }^{61}$ as observed by Prof Bjorntorp. ${ }^{62}$ Everything indicates that hyperactivity of the SNS and hyperactivity of the HPA axis are supporting factors in the pathophysiology of VAS.

The body's energy homeostasis and the function of some organs are modulated by the autonomic nervous system (sympathetic component and parasympathetic). Sympathetic innervation of WAT is well known. ${ }^{63}$ Parasympathetic innervation of VAT was reported based on an experimental study by Kreier et al. ${ }^{64}$ Currently, the role of the parasympathetic nervous system in innervation of VAT has become increasingly evident. ${ }^{65}$ From this information, it can be speculated about the sympathovagal imbalance in the VAT as a possible origin of several alterations such as: lipolysis/lipogenesis, increase in fatty acids, insulin resistance, production of a large number of adipocytokines with different functions in organs and cells. This results in changes in cardiometabolism and increased cardiovascular risk. This sympathovagal imbalance may have its origin in the central nervous system and may contribute to the above-mentioned alterations and to the production of more than 50 adipocytokines (biologically active molecules). ${ }^{66}$ Thus, it seems that WAT keeps up hyperactive and exerts a pleiotropic action ${ }^{66}$ to supply an increased metabolic demand, a consequence of sympathetic hyperactivity ${ }^{47}$ and possible activation of the hypothalamic-pituitary-adrenal axis.

In summary, a primary change in the central nervous system results in increased sympathetic ac- 
tivity, which in turn increases blood pressure and metabolic demand, resulting in a higher concentration of intra-abdominal adipocytes. This higher concentration of intra-abdominal adipocytes supplies the increased metabolic demand at the expense of fatty acids, but results in insulin resistance. Insulin resistance initiates a metabolic imbalance characterised by increased blood glucose, triglycerides, reduced HDL-cholesterol, increased uric acid, lower adiponectin, production of cytokines and hormones with specific action in different organs and cells of the body. Experimental and clinical studies are needed to elucidate the real pathophysiology of the visceral adiposity syndrome and its cardiometabolic consequences.

\section{Acknowledgements}

None.

\section{Conflict of interest}

None.

\section{References}

1. Cannon WB, De La Paz D. Emotional stimulation of adrenal secretion. Am J Physiol 1911;28:64-70.

2. Cameron AJ, Shaw JE, Zimmet PZ. The metabolic syndrome: prevalence in worldwide populations. Endocrinol Metab Clin North Am 2004 Jun;33(2):351-75.

3. Lopes HF, Correa-Giannella ML, Consolim-Colombo FM, Egan BM. Visceral adiposity syndrome. Diabetol Metab Syndr 2016;8:1-8.

4. Leitnera BP, Huanga S, Brychtaa RJ, Duckwortha CJ, Baskina AS, McGeheea S, et al. Mapping of human brown adipose tissue in lean and obese young men. PNAS 2017;114:8649-54

5. Cypess AM, Lehman S, Williams G, T al I, Rodman D, Goldfine $\mathrm{AB}$, et al. Identification and importance of brown adipose tissue in adult humans. N Engl J Med 2009;360:1509-17.

6. Vijgen GHEJ, Bouvy ND, Teule GJJ, Brans B, Hoeks J, Schrauwen $\mathrm{P}$, et al. Increase in brown adipose tissue activity after weight loss in morbidly obese subjects. J Clin Endocrinol Metab 2012 Jul;97(7):E1229-33.

7. Lidell ME, Betz MJ, Enerback S. Brown adipose tissue and its therapeutic potential. J Intern Med 2014;276:364-77.

8. Petrovic N, Walden TB, Shabalina IG, Timmons JA, Cannon B, Nedergaard J. Chronic peroxisome proliferator-activated receptor gamma (PPARgamma) activation of epididymally derived white adipocyte cultures reveals a population of thermogenically competent,
UCP1-containing adipocytes molecularly distinct from classic brown adipocytes. J Biol Chem 2010;285:715364.

9. $\mathrm{Wu}$ J, Cohen P, Spiegelman BM. Adaptive thermogenesis in adipocytes: is beige the new brown? Genes Dev 2013 Feb 1;27(3):234-50.

10. Shao M, Wang QA, Song A, Vishvanath L, Busbuso NC, Scherer PE, et al. Cellular origins of beige fat cells revisited. Diabetes 2019;68:1874-85.

11. Shao M, Gupta RK. Transcriptional brakes on the road to adipocyte thermogenesis. Biochim Biophys Acta Mol Cell Biol Lipids 2019;1864:20-8.

12. Deprès J-P, Moorjani S, Ferland M, Tremblay A, Lupien PJ, Nadeau A, et al. Adipose tissue distribution and plasma lipoprotein levels in obese women: importance of intra-abdominal fat. Arterioscler Thromb Vasc Biol 1989;9:203-10.

13. Ibrahim MM. Subcutaneous and visceral adipose tissue: structural and functional differences. Obes Rev 2010;11:11-8.

14. Dusserre E, Moulin P, Vidal H. Differences in mRNA expression of the proteins secreted by the adipocytes in human subcutaneous and visceral adipose tissues. Biochim Biophys Acta 2000 Jan 3;1500(1):88-96.

15. Linder K, Arner P, Flores-Morales A, Tollet-Egnell P, Norstedt G. Differentially expressed genes in visceral or subcutaneous adipose tissue of obese men and women. J Lipid Res 2004 Jan;45(1):148-54.

16. Reaven GM. Banting lecture 1988. Role of insulin resistance in human disease. Diabetes 1988 Dec;37(12):1595-607.

17. Enzi G, Busetto L, Inelmen EM, Coin A, Sergi G. Historical perspective: visceral obesity and related comorbidity in Joannes Baptista Morgagni's De sedibus et causis morborum per anatomen indagata. Int J Obes Relat Metab Disord 2003;27:534-5.

18. Preble WE. Obesity: observations on one thousand cases. Boston Med Surg J 1923;188:617-21.

19. Vague J. The degree of masculine differentiation of obesities: a factor determining predisposition to diabetes, atherosclerosis, gout, and uric calculous disease. Am J Clin Nutr 1956;4:20-34.

20. Alberti KG, Zimmet PZ. Definition, diagnosis and classification of diabetes mellitus and its complications. Part 1: diagnosis and classification of diabetes mellitus: provisional report of a WHO consultation. Diabet Med 1998;15:539-53.

21. Balkau B, Charles MA. Comment on the provisional report from the WHO consultation: European group for the study of insulin resistance (EGIR). Diabet Med 1999;16:442-3.

22. Expert panel on detection, evaluation, and treatment of high blood cholesterol in adults. Executive summary of The third report of the national cholesterol education program (NCEP) expert panel on detection, evaluation, and treatment of high blood cholesterol in adults (Adult Treatment Panel III). JAMA 2001 May 16;285(19):248697.

23. Alberti KG, Zimmet P, Shaw J. The metabolic syndrome-a new worldwide definition. IDF epidemiology task force consensus group. Lancet 2005;366:1059-62.

24. Ishizaka N, Ishizaka Y, Toda E-I, Nagai R, Yamakado M. Association between serum uric acid, metabolic syndrome, and carotid atherosclerosis in Japanese individuals. Arterioscler Thromb Vasc Biol 2005;25:1038-44.

25. Ryo M, Nakamura T, Kihara S, Kumada M, Shibazaki S, Takahashi M, et al. Adiponectin as a biomarker of the metabolic syndrome. Circ J 2004;68:975-81.

26. Matsuzawa Y, Funahashi T, Kihara S, Shimomura I. 
Adiponectin and metabolic syndrome. Arterioscler Thromb Vasc Biol 2004;24:29-33.

27. Whitehead JP, Richards AA, Hickman IJ, Macdonald GA, Prins JB. Adiponectin-a key adipokine in the metabolic syndrome. Diabetes Obes Metab 2006 May;8(3):26480.

28. Lambert EA, Straznicky NE, Dixon JB, Lambert GW. Should the sympathetic nervous system be a target to improve cardiometabolic risk in obesity? Am J Physiol Heart Circ Physiol 2015;309: H244-H258.

29. Grassi G, Biffi A, Seravalle G, Trevano FQ, Dell'Oro R, Corrao G, et al. Sympathetic neural overdrive in the obese and overweight state meta-analysis of published studies. Hypertension 2019;74:349-58.

30. Björntorp P. Do stress reactions cause abdominal obesity and comorbidities? Obes Rev 2001 May;2(2):73-86.

31. Tentolouris N, Liatis S, Katsilambros N. Sympathetic system activity in obesity and metabolic syndrome. Ann N Y Acad Sci 2006 Nov;1083:129-52.

32. Lopes HF, Bortolotto LA, Szlejf C, Kamitsuji CS, Krieger EM. Hemodynamic and metabolic profile in offspring of malignant hypertensive parents. Hypertension 2001;38:616-20.

33. Feber J, Ruzicka M, Geier P, Litwin M. Autonomic nervous system dysregulation in pediatric hypertension. Curr Hypertens Rep 2014;16:426.

34. Thorp AA, Schlaich MP. Relevance of sympathetic nervous system activation in obesity and metabolic syndrome. J Diabetes Res 2015;2015:341583. doi: $10.1155 / 2015 / 341583$

35. Julius S, Gudbrandsson T, Jamerson K, Andersson 0. The interconnection between sympathetics, microcirculation, and insulin resistance in hypertension. Blood Press 1992 May;1(1):9-19.

36. Pollare T, Lithell H, Selinus I, Berne C. Application of prazosin is associated with an increase of insulin sensitivity in obese patients with hypertension. Diabetologia 1988 Jul;31(7):415-20.

37. Grassi G, Dell'Oro R, Quarti-Trevano F, Scopelliti F, Seravalle G, Paleari F, et al. Neuroadrenergic and reflex abnormalities in patients with metabolic syndrome. Diabetologia 2005 Jul;48(7):1359-65.

38. Gil JS, Drager LF, Guerra-Riccio GM, Mostarda C, Irigoyen $\mathrm{MC}$, Costa-Hong $\mathrm{V}$, et al. The impact of metabolic syndrome on metabolic, pro-inflammatory and prothrombotic markers according to the presence of high blood pressure criterion. Clinics (Sao Paulo) 2013 Dec;68(12):1495-501.

39. Lopes HF, Consolim-Colombo FM, Barreto-Filho JAS, Riccio GMG, Negrão CE, Krieger EM. Increased sympathetic activity in normotensive offspring of malignant hypertensive parents compared to offspring of normotensive parents. Braz J Med Biol Res 2008;41:849-53.

40. Noll G, Wenzel RR, Schneider M, Oesch V, Binggeli C, Shaw $S$, et al. Increased activation of sympathetic nervous system and endothelin by mental stress in normotensive offspring of hypertensive parents. Circulation 1996 Mar 1;93(5):866-9.

41. Grassi G, Ram VS. Evidence for a critical role of the sympathetic nervous system in hypertension. J Am Soc Hypertens 2016;10(5):457-66.

42. Gamboa A, Figueroa R, Paranjape SY, Farley G, Diedrich A, Biaggioni I. Autonomic blockade reverses endothelial dysfunction in obesity-associated hypertension. Hypertension 2016;68:1004-10.

43. Schlaich MP, Kaye DM, Lambert E, Sommerville M, Socratous F, Esler MD. Relation between cardiac sympathetic activity and hypertensive left ventricular hypertrophy. Circulation 2003 Aug 5;108(5):560-5.
44. Head RJ. Hypernoradrenergic innervation: its relationship to functional and hyperplastic changes in the vasculature of the spontaneously hypertensive rat. Blood Vessels 1989;26(1):1-20.

45. Stephens N, Heagert AM. The sympathetic nervous system and small artery neuroeffector function in hypertension. Vascular Medicine Review 1994;5:73-91.

46. Griendling $\mathrm{KK}$, Ushio-Fukai $\mathrm{M}$, Lassègue $\mathrm{B}$, Alexander RW. Angiotensin II signaling in vascular smooth muscle. New concepts. Hypertension 1997 Jan;29(1 Pt 2):366-73.

47. Luke A, Adeyemo A, Kramer H, Forrester T, Cooper RS. Association between blood pressure and resting energy expenditure independent of body size. Hypertension 2004;43:555-60.

48. Ali N, Mahmood S, Manirujjaman M, Perveen R, Al Nahid A, Ahmed S, et al. Hypertension prevalence and influence of basal metabolic rate on blood pressure among adult students in Bangladesh. BMC Public Health 2017 Jul 25;18(1):58.

49. Simonson E, Brozek J. Russian research on arterial hypertension. Ann Intern Med 1959;50:129-93.

50. Ibrahim MM. Subcutaneous and visceral adipose tissue: structural and functional differences. Obes Rev 2010;11:11-8

51. Melzer K. Carbohydrate and fat utilization during rest and physical activity. e-SPEN, the European e-Journal of Clinical Nutrition and Metabolism 6 2011;e45-e52.

52. Luke A, Adeyemo A, Kramer H, Forrester T, Cooper RS. Association between blood pressure and resting energy expenditure independent of body size. Hypertension 2004;43:555-60.

53. Ali N, Mahmood S, Manirujjaman M, Perveen R, Al Nahid A, Ahmed S, et al. Hypertension prevalence and influence of basal metabolic rate on blood pressure among adult students in Bangladesh. BMC Public Health 2017 Jul 25;18(1):58.

54. Motta E Motta J, Souza LN, Vieira BB, Delle H, Consolim-Colombo FM, Egan BM, et al. Acute physical and mental stress resulted in an increase in fatty acids, norepinephrine, and hemodynamic changes in normal individuals: A possible pathophysiological mechanism for hypertension-Pilot study. J Clin Hypertens (Greenwich) 2021 Apr;23(4):888-94.

55. Boden G. Role of fatty acids in the pathogenesis of insulin resistance and NIDDM. Diabetes 1997 Jan;46(1):310.

56. Chueire VB, Muscelli E. Effect of free fatty acids on insulin secretion, insulin sensitivity and incretin effect - a narrative review. Arch Endocrinol Metab 2020 Dec 15:2359-3997000000313.

57. Randle PJ, Garland PB, Hales CN, Newsholme EA. The glucose fatty-acid cycle. Its role in insulin sensitivity and the metabolic disturbances of diabetes mellitus. Lancet 1963;1:785-9.

58. Soroosh GP, Dzaye O, Reiter-Brennan C, Blaha MJ, Cardiometabolic medicine a review of the current proposed approaches to revamped training in the United States. Cardiovascular Endocrinology \& Metabolism 2021; Volume publish ahead of print. doi:10.1097/ XCE.0000000000000243.

59. Alvarez GE, Beske SD, Ballard TP, Davy KP. Sympathetic neural activation in visceral obesity. Circulation 2002 Nov 12;106(20):2533-6.

60. Hillebrand S, Mutsert R, Christen T, Maan AC, Jukema JW, Lamb HJ, et al. Body fat, especially visceral fat, is associated with electrocardiographic measures of sympathetic activation. Obesity 2014;22:1553-9.

61. Tentolouris N, Liatis S, Katsilambros N. Sympathetic 
system activity in obesity and metabolic syndrome. Ann N Y Acad Sci 2006 Nov;1083:129-52.

62. Bjorntorp P. Body fat distribution, insulin resistance, and metabolic diseases. Nutrition 1997;13:795-803.

63. Hucking $\mathrm{K}$, Hamilton-Wessler M, Ellmerer M, Bergman RN. Burst-like control of lipolysis by the sympathetic nervous system in vivo. J Clin Invest 2003;111:257-64.

64. Kreier F, Fliers E, Voshol PJ, Van Eden CG, Havekes LM, Kalsbeek A, et al. Selective parasympathetic innervation of subcutaneous and intra-abdominal fat--func- tional implications. J Clin Invest 2002 Nov;110(9):124350

65. Romijn JA, Fliers E. Sympathetic and parasympathetic innervation of adipose tissue: metabolic implications. Curr Opin Clin Nutr Metab Care 2005 Jul;8(4):440-4.

66. Trayhurn P, Wood IS. Adipokines: inflammation and pleiotropic role of white adipose tissue. Br J Nutr 2004;92:347-55. 